\title{
The affecting factors of childbirth fear for pregnant women admitted to a health center and university hospital in Turkey
}

Childbirth fear of pregnant women

Didem Kaya

Department of Nursing, Faculty of Health Sciences, Nuh Naci Yazgan University, Kayseri, Turkey, and

Funda Evcili

Department of Child Development, Vocational School of Health Care Services, Sivas Cumhuriyet Universitesi, Sivas, Turkey

\begin{abstract}
Purpose - Fear of birth may cause perinatal complication, increased risk of intervention and need for analgesia, delayed mother-infant attachment process and deterioration of spouse relationship. The purpose of this study was to determine the affecting factors and childbirth fears of Turkish pregnant women.

Design/methodology/approach - This is a descriptive research type. The sample of this study consisted of 78 pregnant women who met the inclusion criteria and agreed to participate in this study. This study was carried out in a family health center and university hospital in a city in Turkey. Data were collected with Personal Information Form and Wijma Expectancy/Experience Scale-A Version (W-DEQ A).

Findings - The mean scores of pregnant women from W-DEQ A version were $75.60 \pm 9.48$. In $65.4 \%$ of pregnant women, fear of severe birth, $20.5 \%$ fear of clinical birth and $14.1 \%$ of children had a fear of moderate birth. W-DEQ A version, the third trimester, unplanned pregnancies, lack of knowledge of the level of inadequate birth and more than eight pregnancies in pregnancy, the total score of pregnant women was found to be higher $(p<0.05)$.

Research limitations/implications - The limitation of this study is its small sample size. Further studies with larger sample sizes are needed.

Practical implications - It was determined that one-fifth of the sample group experienced birth fear at the clinical level and childbirth fear level is associated with unplanned pregnancies, lack of knowledge. In antenatal period, the pregnant woman should be encouraged to express her feelings and thoughts about the labor and give information about the labor.

Social implications - Cognitive and behavioral education programs can be structured to cope with fear of birth for pregnant women at risk.

Originality/value - This research is original. This study presents data on Turkish women. The data can also be used to evaluate intercultural differences.
\end{abstract}

Keywords Childbirth, Fear of birth, Pregnant women, Turkey

Paper type Research paper

\section{Introduction}

The birth process presents women with many risks during pregnancy and delivery but also during the postpartum period [1]. Birth and the birthing process is often a cause for anxiety and increasingly requires intervention. Women prefer to hand over responsibility to healthcare professionals rather than trust their bodies and the natural birthing process. As a

(C) Didem Kaya and Funda Evcili. Published in the Journal of Health Research. Published by Emerald Publishing Limited. This article is published under the Creative Commons Attribution (CC BY 4.0) license. Anyone may reproduce, distribute, translate and create derivative works of this article (for both commercial and non-commercial purposes), subject to full attribution to the original publication and authors. The full terms of this license may be seen at $\mathrm{http} / /$ creativecommons.org/licences/by/4.0/legalcode

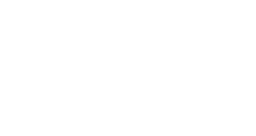


JHR

34,5

390

result, interventional vaginal delivery and cesarean section rates are increasing [2, 3]. Factors causing the fear of childbirth are diverse. Many reasons such as low-income level, lack of social support, lack of trust in healthcare professionals, being alone in a different environment, concerns about the infant's health during the pregnancy period, concerns about postnatal breastfeeding, having a cesarean section and fear of pain increase the fears of a pregnant woman [4-8].

Fear of childbirth can cause many problems such as complications of pregnancy and labor, increased use of analgesia during labor, increased birth interventions, urgent and voluntary cesarean sections, postpartum depression, post-traumatic stress disorder, delay in maternal-infant attachment and deterioration in spousal relations [4]. Additionally, women who experience fear of childbirth during the antenatal period are at greater risk in terms of negative effects that may develop between the mother and infant after delivery. Fear of pain at birth and the fear of failing to get help in case of having pain may be an early predictor of pain and stress during labor. The fear of childbirth observed in the third trimester of pregnancy can also increase the risk of an urgent cesarean section [9].

The aim of interventions for women experiencing fear of childbirth is to support the pregnancy and to control the concerns related to pregnancy and labor. For this purpose, many approaches such as psychoprophylaxis, hypnosis, cognitive-behavioral changeoriented therapeutic interventions and counseling interventions are used. In order to prevent negative effects of the fear of childbirth on the woman/fetus/newborn/family, the support of healthcare services by a multidisciplinary team including nurses, midwives, psychologists, psychiatrists, obstetricians and gynecologists provides useful results. Professional support given by a multidisciplinary team during pregnancy and childbirth may develop a sense of control and confidence and can help a pregnant woman to cope with the fear of childbirth and prevent negative experiences [10]. In order to provide the most effective and efficient care and support, it is necessary to objectively identify the cause of fear for pregnant women in receipt of care related to their impending labor. This study aims to determine the childbirth fear status of Turkish pregnant women and the factors related to the fear of childbirth.

\section{Methodology}

\section{Sample}

This study was conducted as a descriptive research type. There are 29 family health centers in the city center of Sivas. Within the scope of this study, one of these family health centers, the Sivas Orhangazi Family Health Center, was chosen by simple random sampling methodology. The Cumhuriyet University Research and Application Hospital in the city was selected as another study center. The population of this study consisted of the pregnant women who attended the abovementioned institutions and were in the last trimester of their pregnancy between March and July 2018. The study sample consisted of 78 pregnant women who met the inclusion criteria and agreed to participate in this study.

\section{Data collection tools}

The research data were collected using a Personal Information Form and the "Wijma Delivery Expectancy/Experience Questionnaire Version-A (W-DEQ A)”.

Personal Information Form: This was prepared by the researchers to determine the sociodemographic and obstetric characteristics of the pregnant women involved in this study. The form consisted of 12 open-ended and 26 close-ended items.

Wijma Delivery Expectancy/Experience Questionnaire Version-A (W-DEQ A): The Turkish adaptation of the Wijma Delivery Expectancy/Experience Questionnaire VersionA developed by Wijma et al. aimed to determine the level of pregnant women's fear of childbirth as previously conducted by Korukcu et al. [11, 12]. W-DEQ A version is a scale with 
33 items. The responses in the scale are numbered from 0 to 5 on a 6 -point Likert scale. While 0 was referred to as "completely", 5 was referred to as "never". The minimum score was 0 on the scale whereas the maximum score was 165. A high total item score indicated a high level of fear. The cut-off value was 85 points.

(1) W-DEQ score of $\leq 37$ points referred to fear at a mild level,

(2) W-DEQ score of 38-65 points referred to fear at a moderate level,

(3) W-DEQ score of 66-84 points referred to fear at a severe level,

(4) W-DEQ score of $\geq 85$ points referred to a clinical level of fear.

Negatively loaded questions in the scale $(2,3,6,7,8,11,12,15,19,20,24,25,27,31)$ were calculated reversely to provide adaptation in the measurement. The Cronbach's alpha value of the scale was 0.88 for primiparous pregnant women and 0.90 for multiparous pregnant women. In this study, the Cronbach's alpha value obtained from the scale was determined as 0.86 .

\section{Data analysis}

The coding and evaluation of the data were carried out in SPSS 22.0 for Windows packaged software. In addition to descriptive statistical methods (number, percentage, mean, standard deviation), Pearson product-moment correlation analysis, significance test of the difference between two means ( $t$-test) and ANOVA test were used in the assessment of the data. The results were evaluated at a confidence interval of $95 \%$ and a significance level of $p<0.05$.

\section{Ethical consideration}

Before commencing on the study, approval from the Non-invasive Clinical Trials Ethics Committee (2018-02/60) and written permission from the Provincial Health Directorate were obtained. Then, the pregnant women who applied to the study centers and met the inclusion criteria of the study were informed about the purpose of the study and their consent was obtained. It was explained that the data would be published for scientific purposes without stating names. Data collection tools were applied by the researcher to the pregnant women who agreed to participate in the study. A consent form was completed by all participants.

\section{Results \\ Sociodemographic characteristics of the pregnant women}

The mean age of the pregnant women participating in the present study was $27.18 \pm 4.93$. Of all the pregnant women, $38.5 \%$ of them had a high school and above education level and $9 \%$ described their income status as "low". All of the pregnant women had health insurance and $85.9 \%$ of them lived as a nuclear family; $35.9 \%$ of the pregnant women stated that they did not receive social support and $16.7 \%$ stated that they were smokers (Table 1 ).

\section{Obstetric characteristics of the pregnant women}

It was found that the mean gestational week of the pregnant women was $30.28 \pm 4.9$ and $65.4 \%$ of them were in the third trimester; $19.2 \%$ of the pregnancies were unplanned. The mean gravida number of the pregnant women was $2.24 \pm 1.27,6.4 \%$ had a history of curettage, and $24.4 \%$ had a history of abortion. Of all the pregnant women, $32.1 \%$ of them had experienced their first pregnancy and all of them had commenced taking prenatal care from the first trimester. The pregnant women started to receive prenatal care in any health institution at a mean of $10.15 \pm 4.88$ times during their current pregnancy. The pregnant women utilizing prenatal care services received knowledge from healthcare personnel on 


\begin{tabular}{|c|c|c|}
\hline & & \\
\hline JHR & Characteristics & $n(\%)$ \\
\hline & $\begin{array}{l}\text { Age group }(n=78) \\
20-24 \\
25-29 \\
\geq 30 \text { age } \\
\text { The mean age }\end{array}$ & $\begin{array}{c}29(37.2) \\
20(25.6) \\
29(37.2) \\
27.18 \pm 4.93\end{array}$ \\
\hline & Education status $(n=78)$ & \\
\hline & $\begin{array}{l}\text { Elementary school and below } \\
\text { High school and above }\end{array}$ & $\begin{array}{l}48(61.5) \\
30(38.5)\end{array}$ \\
\hline & $\begin{array}{l}\text { Income status }(n=78) \\
\text { Good } \\
\text { Middle } \\
\text { Low }\end{array}$ & $\begin{array}{l}27(34.6) \\
44(56.4) \\
7(9.0)\end{array}$ \\
\hline & $\begin{array}{l}\text { Family type }(n=78) \\
\text { Nuclear family } \\
\text { Extended family }\end{array}$ & $\begin{array}{l}67(85.9) \\
11(14.1)\end{array}$ \\
\hline e 1. & $\begin{array}{l}\text { Perceived social support }(n=78) \\
\text { Yes } \\
\text { No }\end{array}$ & $\begin{array}{l}50(64.1) \\
28(35.9)\end{array}$ \\
\hline $\begin{array}{l}\text { characteristics of } \\
\text { pregnant } \\
\text { women }(n=78)\end{array}$ & $\begin{array}{l}\text { Smoking }(n=78) \\
\text { Yes } \\
\text { No }\end{array}$ & $\begin{array}{l}13(16.7) \\
65 \text { (83.3) }\end{array}$ \\
\hline
\end{tabular}

three main subjects, namely, postpartum contraception $(87.2 \%)$, preparation (83.3) and physical changes during pregnancy (83.3). Of all the pregnant women, $57.7 \%$ of them found their knowledge level about pregnancy to be "insufficient" and $39.7 \%$ of them found their knowledge level about childbirth to be "insufficient". Among the sources from which the pregnant women obtained knowledge about childbirth, friends $(97.4 \%)$, relatives $(93.6 \%)$ and newspapers/books/magazines $(92.3 \%$ ) were the most frequent responses (Table 2 ).

\section{Scale mean scores of the pregnant women}

The W-DEQ A Version mean scores of the pregnant women were $75.60 \pm 9.48$. Of all the pregnant women, $65.4 \%$ of them had severe levels of childbirth fear, $20.5 \%$ had clinical levels of childbirth fear and 14.1\% had moderate levels of childbirth fear (Tables 3 and 4).

Scale total mean score according to some characteristics of the pregnant women

No statistically significant difference was found between the W-DEQ A Version total mean scores in terms of the age groups, educational level, income level and getting social support in the current pregnancy $(p>0.05)$. Besides, the W-DEQ A Version total mean scores of the pregnant women who were in the third trimester and recorded that theirs was an unplanned pregnancy, found their knowledge level about labor insufficient, and that pregnancy monitoring $\geq 8$ times before the birth was found to be high $(\phi<0.05)$ (Table 5).

Correlation scale total mean score according to some characteristics of the pregnant women A statistically significant positive correlation was found between the scores of the pregnant women from W-DEQ A Version and the number of pregnancy follow-ups, number of gravidae, number of parity and the gestational week $(p<0.05)$. As the numbers of pregnancy 
Obstetric characteristics

Pregnancy Trimester

1. Trimester

2. Trimester

3. Trimester

Gestational week mean

Planned status of pregnancy

Planned

Unplanned

Getting prenatal care

1. Trimester

Number of follow-ups in pregnancy

$<8$ times

$\geq 8$ times

Topics of interest ${ }^{*}$

Postpartum contraception

Preparation for childbirth

Physical changes in pregnancy

Emotional changes in pregnancy

Newborn care

Exercise during pregnancy

Fetus growth and development

Breastfeeding counseling

Signs of danger in pregnancy

Nutrition in pregnancy

Sufficient finding of knowledge level about pregnancy

Sufficient

Insufficient

Partially sufficient

Sufficient finding of knowledge level about childbirth

Sufficient

Insufficient

Partially sufficient

Sources of knowledge about childbirth ${ }^{*}$

Friends

Relatives (mother, neighbor, etc.)

Newspaper/book/magazine

Health professionals

Internet/television

Note(s): "It was determined according to the statement of the pregnant woman; multiple options marked, percentages were taken over "n"

$76(97.4)$
Childbirth fear

of pregnant

women

$27(34.6)$

$51(65.4)$

$30.28 \pm 4.9$

$63(80.8)$

$15(19.2)$

78 (100.0)

$30(38.5)$

48 (61.5)

$68(87.2)$

65 (83.3)

65 (83.3)

$63(80.8)$

$62(79.5)$

$62(79.5)$

56 (71.8)

$55(70.5)$

37 (47.4)

$20(25.6)$

26 (33.3)

45 (57.7)

$7(9.0)$

20 (25.6)

31 (39.7)

27 (34.6)

73 (93.6)

$72(92.3)$

$63(80.8)$

$62(79.5)$

Table 2.

Obstetric characteristics of pregnant women $(n=78)$

\begin{tabular}{lccc}
\hline & Scale min-max score & Study min-max score & $\mathrm{m}(\mathrm{sd})$ \\
\hline W-DEQ A* & $0-165$ & $51-93$ & $75.60 \pm 9.48$
\end{tabular}

Note(s): "W-DEQ A: Wijma Delivery Expectancy/Experience Questionnaire Version A

Table 3.

W-DEQ A Version total score mean of pregnant women $(n=78)$ 
JHR

34,5

394

Table 4.

Birth fear according to W-DEQ A Version score of pregnant women $(n=78)$ follow-up, gestational week, gravida and parity increased, the childbirth fear increased, as well (Table 6).

\section{Discussion}

Fear of childbirth is an important issue that requires closer attention because of its relationship with pregnancy complications, poor birth experience and postpartum emotional problems [4]. Fear of childbirth adversely affects maternal/fetal/neonatal health [13]. The WDEQ A Version total mean score of the pregnant women participating in the present study was $75.60 \pm 9.48$. Women having a W-DEQ A score of 66-84 are considered to have severe levels of childbirth fear. According to this result, it was determined that the women included in the present study experienced a severe level of childbirth fear.

It was determined that the childbirth fears of the women who were in the present study and were in the third trimester of pregnancy were higher $(\phi<0.05)$. The result found in the study by Sen $\mathrm{et}$ al. indicating that $62.5 \%$ of the women in the last trimester experienced fear of childbirth supports the result of the present study [14]. Research shows that women focus on pregnancy in the first trimester, the infant in the second trimester and delivery in the third trimester [15]. Furthermore, anxiety levels increase during the third trimester of pregnancy [8]. It was found that as the numbers of gravida and parity of the pregnant women participating in the present study increased, the fear of childbirth also increased $(p<0.05)$. Similar to the result of the present study, Sahin et al. found in their study that the fear of childbirth increased statistically as the number of parity of the pregnant women increased [16]. Experiencing negative events by multiparous pregnant women from their previous pregnancies caused them to experience fear of childbirth $[15,17]$. It was determined as a result of the study conducted by Mazúchová et al. that childbirth fear of primiparous pregnant women was higher compared to multiparous women [18]. High levels of fear in primiparous pregnant women can be attributed to the fear of the unknown.

The childbirth fear of pregnant women who found their knowledge levels about labor to be insufficient was found to be high in the present study $(\phi<0.05)$. Soltani et al. determined that women who did not have enough knowledge about labor experienced more fear of childbirth which supports the result of the present study [19]. It has been determined in the literature that the training given during the prenatal period reduces the fear of childbirth of pregnant women $[20,21]$. Reducing the fear of the unknown can be achieved by increasing the level of knowledge on the subject. The knowledge given by the healthcare personnel in the prenatal period in accordance with the needs of the pregnant women contributes to the reduction of their fear levels [22].

Prenatal care (PNC) involves the monitoring of the mother and fetus by a trained health worker at regular intervals throughout the pregnancy while providing necessary examinations and recommendations. The main objective of the PNC process is to ensure that expectant mothers experience a healthy pregnancy and give birth to healthy babies [23]. In the pregnancy follow-up standardized by the Ministry of Health in the content of "Safe Motherhood", at least four follow-ups were accepted for all pregnant women who were not in the at risk category [24]. Periodic follow-up and examinations during the pregnancy period provides unique opportunities for healthcare professionals to reach pregnant women. With

\begin{tabular}{lcccc}
\hline W-DEQ A & $\begin{array}{c}\text { Light }(\leq 37) \\
n(\%)\end{array}$ & $\begin{array}{c}\text { Moderate }(38-65) \\
n(\%)\end{array}$ & $\begin{array}{c}\text { Severe }(66-84) \\
n(\%)\end{array}$ & $\begin{array}{c}\text { Clinical }(\geq 85) \\
n(\%)\end{array}$ \\
\hline $\begin{array}{l}\text { Fear of birth } \\
\text { Note(s): * W-DEQ A: Wijma Delivery }\end{array}$ & $\begin{array}{c}11(14.1) \\
\text { Expectancy/Experience Questionnaire Version A }\end{array}$ & $16(20.5)$ \\
\end{tabular}


Characteristics

Sociodemographic characteristics

Age groups

$20-24$ age $(n=29)$

$25-29$ age $(n=20)$

$\geq 30$ age $(n=29)$

Education status

Elementary and below $(n=48)$

High school and above $(n=30)$

Income status

Good $(n=27)$

Medium $(n=44)$

Low $(n=7)$

Perceived social support

Sufficient $(n=50)$

Insufficient $(n=28)$

\section{Obstetrical characteristics}

Pregnancy trimester

2. Trimester $(n=27)$

3. Trimester $(n=51)$

Pregnancy follow-up

$<8$ times

$\geq 8$ times

Planned status of pregnancy

Planned $(n=63)$

Unplanned $(n=15)$

Sufficient finding of knowledge level about pregnancy

Sufficient $(n=26)$

Insufficient $(n=45)$

Partially sufficient $(n=7)$

Sufficient finding of knowledge level about childbirth

Sufficient $(n=20)$

Insufficient $(n=31)$

Partially sufficient $(n=27)$
W-DEQ A* m (sd)

$t / F$

$p$

Childbirth fear

of pregnant

women

$75.51 \pm 9.40$

$77.90 \pm 10.06$

$74.10 \pm 9.17$

0.949

0.392

$76.66 \pm 10.48$

$73.90 \pm 7.45$

$74.85 \pm 7.85$

$75.84 \pm 11.06$

$77.00 \pm 2.00$

0.171

0.843

$75.18 \pm 10.36$

0.523

$76.35 \pm 7.78$

1.258

0.212

$72.96 \pm 7.90$

1.815

0.043

$77.00 \pm 10.01$

$71.30 \pm 8.08$

$78.29 \pm 9.37$

3.375

0.001

$75.49 \pm 9.89$

$78.06 \pm 7.79$

1.210

0.035

$73.88 \pm 8.99$

$76.42 \pm 9.17$

$76.71 \pm 13.43$

0.637

0.532

$71.15 \pm 8.45$

$78.77 \pm 9.67$

$75.70 \pm 9.06$
Table 5.

W-DEQ A Version total score mean of pregnant women according to some characteristics $(n=78)$

\begin{tabular}{|c|c|c|}
\hline Characteristics & $\mathrm{r}^{\mathrm{a}}$ & $\mathrm{P}$ \\
\hline Pregnancy follow-up & 0.246 & 0.030 \\
\hline Gravida & 0.239 & 0.035 \\
\hline Parity & 0.329 & 0.003 \\
\hline Gestational week & 0.352 & 0.002 \\
\hline
\end{tabular}

Note(s): "W-DEQ A, Wijma Delivery Expectancy/Experience Questionnaire Version A; ${ }^{\text {a }}$ Pearson's correlation coefficient

Table 6. Correlation of W-DEQ A Version total mean scores with some characteristics of pregnant women 
adequate health training provided during these follow-ups, pregnant women can be supported and strengthened at the determined subjects and the points they need. Training that includes support in determining the fear and concerns of pregnant women about childbirth and preparing them for labor can result in a more positive pregnancy and birth experience. However, it was found in this study that the fear of childbirth of pregnant women increased as the frequency of prenatal follow-ups increased $(p<0.05)$. The study conducted by Keklikci supports the results of the present study where pregnant women with high fear of childbirth had also experienced more doctor, nurse and midwife examinations [25]. Based on this data, it can be deduced that healthcare professionals do not effectively implement their health training roles and do not offer supportive care initiatives to reduce the concerns/fears of pregnant women. Moreover, it was determined in the present study that pregnant women with unplanned pregnancies experience higher levels of fear of childbirth $(p<0.05)$.

\section{Conclusion}

Fear of birth is a condition that prevents the attachment of the mother-baby, adversely affecting pregnancy, labor and the postpartum processes. In the antenatal period, the pregnant woman should be encouraged to express her feelings and thoughts about the labor and receive care and support about the labor and postdelivery process.

\section{Limitations}

The limitation of this study was its small sample size. Further studies with larger sample sizes would be beneficial in order to conduct a more detailed analysis.

Financial disclosure. The authors declared that this study received no financial support.

Conflict of interest. No conflict of interest was declared by the authors.

\section{References}

1. Taskin L. Obstetrics and gynecology nursing. Ankara: System Offset Printing; 2002.

2. Sercekus P. Intervention to fear of birth: hypnobirthing. TAF Prev Med Bull. 2011; 10(2): 239-42. (in Turkish).

3. Sercekus P, Mete S. Effects of antenatal education on maternal prenatal and postpartum adaptation. J Adv Nurs. 2010 May; 66(5): 999-1010. doi: 10.1111/j.1365-2648.2009.05253.x.

4. Gulec D, Ozturk R, Sevil Ü, Kazandi M. The relationship between fear of birth and perceived social support of pregnant women. Turkiye Klinikleri J Gynecol Obst. 2014; 24(1): 36-41. (in Turkish).

5. Saisto T, Halmesmäki E. Fear of childbirth: a neglected dilemma. Acta Obstet Gyn Scan. 2003 Mar; 82(3): 201-8. doi: 10.1034/j.1600-0412.2003.00114.x.

6. Szeverenyi P, Poka R, Hetey M, Torok Z. Contents of childbirth-related fear among couples wishing the partner's presence at delivery. J Psychosom Obst Gyn. 1998 Mar; 19(1): 38-43. doi: 10. 3109/01674829809044219.

7. Saisto T, Ylikorkala O, Halmesmaki E. Factors associated with fear of delivery in second pregnancies. Obstet Gynecol. 1999 Nov; 94(5): 679-82. doi: 10.1016/S0029-7844(99)00413-5.

8. Kitapcioglu G, Yanikkerem E, Sevil U, Yuksel D. Fear of childbirth and the postpartum period: a scale development and validation study. Meandros Med Dent J. 2008; 9(1): 47-54.

9. Fenwick J, Gamble J, Nathan E, Bayes S, Hauck Y. Pre- and postpartum levels of childbirth fear and the relationship to birth outcomes in a cohort of Australian women. J Clin Nurs. 2009 Mar; 18(5): 667-77. doi: 10.1111/j.1365-2702.2008.02568.x. 
10. Karacam Z, Akyuz EO. Supportive care in labor and the rol of midwife / nurse. Florence Nightingale Journal of Nursing. 2011; 19(1): 45-53. (in Turkish).

11. Wijma K, Wijma B, Zar M. Psychometric aspects of the W-DEQ; a new questionnaire for the measurement of fear of childbirth. J Psychosom Obstet Gynaecol. 1998 Jun; 19(2): 84-97. doi: 10. 3109/01674829809048501.

12. Korukcu O, Kukulu K, Firat MZ. The reliability and validity of the Turkish version of the Wijma Delivery Expectancy/Experience Questionnaire (W-DEQ) with pregnant women. J Psychiatr Ment Health Nurs. 2012 Apr; 19(3): 193-202. doi: 10.1111/j.1365-2850.2011.01694.x.

13. Glover V, O'Connor TG. Effects of antenatal stress and anxiety: implications for development and psychiatry. Br J Psychiatry. 2002 May; 180: 389-91. doi: 10.1192/bjp.180.5.389.

14. Sen E, Dal NA, Dag H, Senveli S. The reasons for delivery: related fear and associated factors in western Turkey. Nurs Pract Today. 2015; 2(1): 25-33.

15. Cicek O, Mete S. A common problem: fear of childbirth. Dokuz Eylül University School of Nursing Electronic Journal. 2015; 8(4): 263-8, (in Turkish).

16. Sahin N, Dinc H, Dissiz M. Pregnant women's fear of childbirth and related factors. Zeynep Kamil Medical Bulletin. 2009; 40(2): 57-62, (in Turkish).

17. Melender HL. Experiences of fears associated with pregnancy and childbirth: a study of 329 pregnant women. Birth. 2002 Jun; 29(2): 101-11. doi: 10.1046/j.1523-536x.2002.00170.x.

18. Mazúchová L, Škodová Z, Kelčíková S, Rabárová A. Factors associated with childbirth - related fear among Slovak women. Cent Eur J Nurs Midw. 2017; 8(4): 742-8. doi: 10.15452/CEJNM.2017. 08.0027.

19. Soltani F, Eskandari Z, Khodakarami B, Parsa P, Roshanaei G. Factors contributing to fear of childbirth among pregnant women in Hamadan (Iran) in 2016. Electron. Physician. 2017; 9(7): 4725-31. doi: 10.19082/4725.

20. Gokce Isbir G, Inci F, Onal H, Yildiz PD. The effects of antenatal education on fear of childbirth, maternal self-efficacy and post-traumatic stress disorder (PTSD) symptoms following childbirth: an experimental study. Appl Nurs Res. 2016 Nov; 32: 227-32. doi: 10.1016/j.apnr.2016.07.013.

21. Ucar T. The effect of based on cognitive behavioral techniques coping with fear of childbirth education program on pregnant women's birth fears and birth process. Sivas, Turkey: Cumhuriyet University; 2014.

22. Gungor I, Gokyildiz S, Nahcivan N. Opinions of a group of women who had caesarean sections about their births and their problems in the early postpartum period. Florence Nightingale Journal of Nursing. 2004; 13(53): 185-98, (in Turkisk).

23. Sonmez Y. Prenatal care services. STED. 2007; 16: 9-12.

24. Ministry of Health. Prenatal care management guide. Ankara: Turkey Public Health, Women and Reproductive Health Department; 2014.

25. Keklikci S. Fear of birth in primipara and determination of factors affecting. Gaziantep, Turkey: Sanko University; 2018.

\section{Corresponding author}

Funda Evcili can be contacted at: fundaevcili@hotmail.com
Childbirth fear of pregnant women 